\title{
O QUE PRECISA SABER UM PROFESSOR DE HISTÓRIA?
}

\author{
WHAT A HISTORY TEACHER NEEDS TO KNOW?
}

Flávia Eloisa Caimi ${ }^{1}$

\begin{abstract}
RESUMO: O presente artigo resulta de um estudo bibliográfico em que se dialoga com autores do campo da História, do Ensino da História e da Educação, com o propósito de problematizar algumas das principais demandas que se apresentam ao trabalho do professor de História, diante da diversidade e complexidade das práticas sociais e culturais que adentram a escola na contemporaneidade. Parte-se do pressuposto de que a História como disciplina escolar contempla potencialidades educativas fundamentais para a formação das novas gerações. Nessa perspectiva, defende-se a centralidade do professor como um agente mediador decisivo na concretização das finalidades educativas desta disciplina e questiona-se acerca de quais conhecimentos e capacidades um professor de História precisa manejar para dar conta das exigências que emergem dos atuais contextos social e escolar. No raciocínio empreendido, elenca-se três principais conjuntos de saberes a serem mobilizados na docência em História: 1) os saberes a ensinar, circunscritos na própria história, na historiografia, na epistemologia da história, dentre outros; 2) os saberes para ensinar, que dizem respeito, por exemplo, à docência, ao currículo, à didática, à cultura escolar; 3) os saberes do aprender, que se referem ao aluno, aos mecanismos da cognição, à formação do pensamento histórico etc.
\end{abstract}

Palavras-chave: Ensino. Aprendizagem. História. Professor.

\begin{abstract}
This article is the result of a bibliography study in which there is a dialogue with authors in the History, History Teaching and Educations fields of study and aims to discuss some of the main demands existing in the History Teacher work, considering the diversity and the complexity of the cultural and social practices present in the schools nowadays. The beginning point is the conception that the History, as a school subject, has fundamental educative potential to new generations formation. Under this perspective, we defend the centrality of the teacher as a decisive mediator in the achievement of the educational goals of the subject. We also question which knowledge and capacities a History teacher needs to handle to deal with the demands that emerges from the social and scholar context. As a result of this line of reasoning, we can point the main knowledge demanded in the History teaching: 1) the knowledge to teach, derived from History, Historiography, Historical Epistemology etc.; 2) the knowledge for teaching, regarding teaching practice, curriculum, didactic, scholar culture; 3) the learning knowledge, which refer to the student, the cognitive mechanisms, historical thought formation etc.
\end{abstract}

Keywords: Education. Learning. History. Teacher.

\footnotetext{
1 Professora do Programa de Pós-Graduação em Educação - Mestrado e Doutorado - da Universidade de Passo Fundo (UPF). Doutora em Educação pela Universidade Federal do Rio Grande do Sul (UFRGS) e pós-doutora pela Facultad Latinoamericana de Ciencias Sociales (Flacso-Argentina).
} 


\section{Introdução}

O título deste artigo pode suscitar no leitor a (des)confiança acerca da viabilidade de se responder a uma pergunta tão ambiciosa, afinal, o que precisa saber um professor de História depende de muitas variáveis, como, por exemplo, as demandas sociais em cada época, os preceitos disseminados pelas políticas educacionais públicas, os diferentes contextos escolares, as especificidades cognitivas e culturais dos estudantes, para citar apenas algumas. O tom adotado no título também pode ensejar a expectativa de que se vai oferecer um conjunto de prescrições sobre as condutas mais adequadas, bastando segui-las para dar conta da docência e obter o sucesso almejado.

Numa perspectiva mais modesta do que o título pode aludir, o propósito do estudo consubstancia-se na tarefa de problematizar algumas das principais demandas que se apresentam ao trabalho do professor de História, diante da pluralidade e complexidade das práticas sociais e culturais que adentram a escola na contemporaneidade. A escola brasileira, abrigando mais de 54 milhões de estudantes e cerca de dois milhões de professores na educação básica, tem se configurado como um lugar altamente desafiador para a docência. Isso porque a diversidade torna cada vez mais evidente a distância entre as culturas juvenis (PAIS, 1996) e a cultura escolar (FORQUIN, 1993) e amplifica a percepção da crise na educação escolar. Essa suposta crise se caracteriza, dentre outros aspectos, pela carência de sentido das propostas do sistema escolar perante os jovens, pela aparência obsoleta dos conteúdos, pela irrelevância de muitas das atividades que ali são desenvolvidas.

Neste cenário complexo e plural, temos muitas perguntas e poucas respostas. Refiro-me não apenas a perguntas-respostas individuais, àquelas indagações que cada professor tem de formular e procurar responder no contexto específico em que atua. Trato aqui da expectativa de construirmos respostas em âmbito coletivo, que advenham de possíveis consensos, de acordos mínimos, mesmo que provisórios, sobre o que/como entendemos que deva ser a disciplina História na escola. Como disse, as perguntas são muitas, algumas das quais sistematizo aqui: para que serve ensinar/aprender História hoje na escola básica, considerando-se os contextos de existência dos nossos alunos e as 
especificidades da cultura escolar? Como torná-la disciplina envolvente, significativa e próxima dos interesses dos jovens? Que conteúdos e procedimentos são os mais potentes para provocar a mobilização intelectual dos jovens para a aprendizagem histórica? Como conciliar o nível de abstração elevado que o seu estudo requer, com as possibilidades cognitivas dos estudantes? Quais conhecimentos e competências devem orientar os processos de formação inicial e continuada de professores de História para dar conta das exigências dessa disciplina escolar? Que critérios de seleção utilizar perante a vastidão de conteúdos e de potencialidades da História escolar? Que modelos curriculares podem ser, potencialmente, mais apropriados para cada um dos segmentos finais da educação básica? A perspectiva cronológica ou a temática se mostra mais adequada para o ensino fundamental? E para o ensino médio? $\mathrm{O}$ que se perde e o que se ganha com uma ou outra opção em cada segmento? Em que medida as dificuldades convencionais de operação nas escolas, tais como a heterogeneidade da formação nos níveis/séries precedentes; a precariedade no domínio das ferramentas de leitura e escrita; o contexto de violência, evasão, defasagem série-idade; as relações conflituosas entre professores e alunos, dentre outros, impactam sobre o ensino e a aprendizagem da História? Como fazer frente a tais dificuldades, de modo que elas não inviabilizem a aprendizagem histórica?

Mais uma vez, preciso alertar o leitor de que esse conjunto de perguntas não será respondido aqui, não só pelos limites de espaço no artigo, mas principalmente pela impossibilidade de respondê-las sem ser prescritivo, normativo, seletivo.

\section{Finalidades educativas da História Escolar nas sociedades contemporâneas}

$\mathrm{Na}$ contemporaneidade em que nos inscrevemos, a História-Conhecimento tem um importante papel, não mais como "mestra da vida" (magistra vitae) conforme a definiu Cícero, mas como um conhecimento que se pode mobilizar para dar inteligibilidade e justificação para o tempo presente, ou, como ensina 
Rüsen (2001), para conhecermos a nós e aos outros, explicar o mundo, nos orientar na vida prática cotidiana e enfrentar as suas contingências².

Ampliando o escopo de justificação da presença da História na escola, revisitemos alguns postulados de Prats $(2006$; 2007) para quem a História possui um interesse próprio e autossuficiente como disciplina de grande potencialidade formativa, sendo cada vez mais necessária para formar pessoas com critério. Dentre outras possibilidades, selecionamos alguns dos principais argumentos que o autor destaca para justificar a história escolar:

a) facilitar a compreensão do presente, uma vez que tudo no presente pode ser melhor compreendido pelo estudo do passado. Porém, alerta-se para o fato de não termos acesso direto ao presente pela História, já que ela apenas nos forneceria as chaves de funcionamento do passado, com as quais podemos compreender o tempo presente;

b) preparar os alunos para a vida adulta, na medida em que a História oferece um marco de referência para entender os problemas sociais, reconhecer a importância dos acontecimentos cotidianos, operar criticamente as informações de modo a desenvolver consciência cidadã plena;

c) despertar o interesse pelo passado, resguardando-se que História e passado não são conceitos sinônimos, mas assinalando que a primeira coloca questões fundamentais sobre o passado com base nas demandas do presente, o que produz reflexão e compromisso sobre este passado;

d) potencializar nas crianças e adolescentes um sentido de identidade e contribuir para o conhecimento e a compreensão de outros países e culturas do mundo atual, já que pela consciência das origens distintas e diversas, os jovens podem compartilhar valores, costumes, ideias etc., e também valorizar as diferenças com atitudes de respeito e tolerância;

\footnotetext{
2 Esse entendimento de que podemos aprender com a História não é compartilhado por alguns autores, como Gumbrecht (2011), quando discute um paradoxo contemporâneo. Diz o autor: "Vivemos uma situação ambivalente: um crescente fascínio pela história e pelo passado, de um lado, e um ceticismo enorme quanto à possibilidade de a história ou a historiografia ensinarem" (p. 26). Gumbrecht tenta explicar a perda da convicção de que a História tem algo a nos ensinar mencionando alguns indicadores, como o fato de os personagens históricos não se constituírem mais em modelos de atuação e a descrença na possibilidade de identificar leis e regularidades na transformação histórica, por exemplo. Assim, o interesse pelo passado estaria circunscrito a razões estéticas e antropológicas, mas não seria um interesse pragmático movido pela expectativa de encontrar orientação para a vida prática.
} 
e) contribuir para o desenvolvimento das faculdades mentais por meio do estudo disciplinado, na medida em que se operaria, na história escolar, com a investigação rigorosa e sistemática das experiências humanas pretéritas, num exercício intelectual que fomenta a formulação de opiniões e análises racionais sobre tais experiências;

f) introduzir os alunos em um conhecimento e no domínio de uma metodologia rigorosa, própria dos historiadores, que estimula as capacidades de análise, argumentação, comparação, inferência, formulação de hipóteses, dentre outras;

g) por fim, enriquecer outras áreas do currículo, uma vez que a História pode subsidiar estudos em diversas disciplinas que são mais bem compreendidas se contextualizadas historicamente, em suas origens e fazeres científicos.

Mediante tais justificativas para a presença da História no currículo escolar da educação básica - num seleto rol de aproximadamente nove disciplinas que figuram nos anos finais do ensino fundamental e cerca de doze disciplinas que constituem a matriz curricular padrão no ensino médio -, não se pode ignorar a centralidade do papel do professor como um agente mediador decisivo (ACOSTA, 2013) nos processos de ensino-aprendizagem escolar.

Nas últimas décadas, os processos de mudança social e as políticas de transformação educativa têm feito com que os requerimentos para o desempenho dos professores sejam mais complexos e exigentes. Os docentes em geral, não só os que atuam na disciplina História, são hoje chamados a exercer o seu trabalho com níveis mais altos de autonomia, o que traz novas e maiores exigências, muitas das quais de caráter burocrático. Exige-se do professor disposição (e competência) para trabalhar de forma integrada a outras disciplinas e áreas do conhecimento, uma vez que o trabalho docente é de natureza social. Exige-se um domínio disciplinar que os habilite a não oferecer respostas únicas, considerando-se a dinamicidade da produção e disseminação do conhecimento na atualidade. Ainda, exige-se do professor um forte compromisso ético, político, social e técnico, diante dos resultados da aprendizagem de seus alunos. Se em outras épocas bastava ensinar, cada vez mais se exigem índices positivos nos processos educativos, índices que são rigorosamente controlados por mecanismos públicos de avaliação em larga escala (CHARLOT, 2013). 
As reformas educativas implementadas no Brasil nos anos 1990 e 2000, notadamente, também trazem demandas específicas aos professores de História, como, por exemplo, a incorporação de novos temas e conteúdos no currículo escolar, oriundos da renovação historiográfica, face ao incremento da produção acadêmica na área específica; o reconhecimento do novo lugar que ocupam os conteúdos escolares, entendidos como meios e não como fins em si mesmos, exige que se operem recortes na vastidão de conhecimentos históricos disponíveis; as exigências de trabalhar com metodologias ativas do campo pedagógico, que assegurem maior protagonismo dos estudantes em seus percursos de aprendizagem, de modo a superar a perspectiva enciclopedista, verbalista e assentada apenas na memorização do passado que tem marcado esta disciplina; o uso de metodologias próprias do campo da investigação historiográfica, que aproximem os estudantes do ofício do historiador, como o trabalho com fontes históricas em sala de aula; a atenção a temas que dizem respeito aos novos sujeitos que adentram à escola, especialmente à diversidade de grupos étnicos e culturais e às questões de gênero, por exemplo.

Ainda que tais demandas figurem nos documentos oficiais e na literatura acadêmica, as mudanças não se materializaram de modo generalizado nas aulas de História, isso por várias razões: muitas das demandas não são subsidiadas na formação inicial nem acompanhadas da necessária formação em serviço dos professores; ao mesmo tempo em que houve um incremento no volume e na complexidade da produção do conhecimento histórico, ocorreu uma expressiva redução de carga horária na disciplina História, que foi impelida a destinar parte de seus períodos para as disciplinas de Sociologia e Filosofia, quando se determinou a obrigatoriedades destas no currículo escolar do ensino médio; as mudanças curriculares propostas na esfera das políticas públicas, embora alicerçadas em sólidos referenciais epistemológicos, nem sempre são apropriadas com a mesma clareza pelos professores, resultando em situações que apontam para a renovação de alguns conteúdos ou da assunção de um ideário tido como progressista, que não se ampara efetivamente na concretização das novas concepções epistemológicas e teóricas relativas ao domínio da ciência de referência; por fim, mesmo que nos últimos anos se tenha implementado programas importantes no âmbito da formação de professores, a exemplo do 
Programa Institucional de Bolsa de Iniciação à Docência - PIBID, permanece escassa a relação/interlocução entre os cursos de formação e as práticas escolares, o que resulta em acentuada dissociação teoria-prática. Não obstante a relevância de todas essas razões, entendo que os professores só mudam suas práticas pedagógicas quando efetivamente vislumbram que elas podem funcionar melhor se geridas de outra forma, e quando acreditam que, geridas de outro modo, podem promover aprendizagens mais qualificadas nos seus alunos. Uma vez que estejam convencidos da necessidade e da viabilidade da mudança, empreendem a luta pelas condições de trabalho, pelo tempo de planejamento, pelos materiais didáticos, dentre outros requisitos.

O desafio de ensinar História neste contexto plural e complexo que emerge na contemporaneidade também interpela as instituições de formação docente, obrigando-as a redefinir acordos mínimos para formar os futuros professores. Nesse sentido, compartilho fortemente do entendimento de Barros (2008, p. 209) quanto ao lugar central do professor nos processos de aprender- ensinar História na escola, ao afirmar que

la docência es, se quiera o no, una parte cardinal del processo de conocer la historia, salvo que se niegue su carácter social, reduciendo el saber histórico a la pura erudición. La enseñanza de la historia, y sus comunidades de aprendizaje, es una actividad creativa y difícil que condiciona, y retroalimenta, la fase investigadora del proceso de reconstrucción del passado.

Assim, recoloca-se a pergunta: que conhecimentos e capacidades um professor de História precisa manejar para dar conta das exigências que emergem dos atuais contextos social e escolar? É esta a questão sobre a qual me debruçarei na seção a seguir.

\section{Para ensinar História a João é preciso entender de ensinar, de História e de João}

Vejo-me impelida, novamente, a explicar o título que adoto nesta seção, pois não se pode ler essa afirmação tão contundente como se os três elementos nele contidos fossem suficientes para elucidar os fazeres do professor de 
História. Para ensinar História não basta, por suposto, possuir conhecimentos históricos, ter alguma formação pedagógica ou conhecer algo de psicologia da aprendizagem. Tenho utilizado essa frase de efeito para chamar a atenção de meus interlocutores da necessidade de superar visões reducionistas que defendem a supremacia do domínio do conhecimento histórico na tarefa docente ou que indicam a suficiência dos saberes pedagógicos em detrimento do saber disciplinar, ou ainda que valorizam prioritariamente o polo discente, posição traduzida na retórica de que é preciso "conhecer a (e partir da) realidade do aluno".

Então, supondo-se que o domínio unilateral de um ou de outro elemento não é suficiente para conduzir a docência, vamos focalizar nesses três aspectos para refletir sobre a natureza do nosso trabalho: 1) os saberes a ensinar: história, historiografia, epistemologia e outros; 2) os saberes para ensinar: docência, currículo, didática, cultura escolar e outros; 3) os saberes do aprender: aluno, cognição, pensamento histórico e outros.

Antes de prosseguir, cabe um esclarecimento sobre o que se está entendendo por "ensinar". Em sentido lato, a ação de ensinar pode ser entendida como "prática social de comunicação e intercâmbio de conteúdos culturais que são obtidos em um meio institucionalizado e com valores relacionados com a cultura" (ACOSTA, 2013, p. 199). Em sentido mais estrito, pode-se entender a ação de ensinar também como o conjunto de tarefas que o professor realiza cotidianamente, como "avaliar, preparar as aulas, elaborar unidades e materiais, controlar o grupo de alunos na classe, manter a disciplina, relacionar-se com os pais, colaborar na organização das escolas, realizar trabalhos com os alunos fora da escola (...) etc." (ACOSTA, 2013, p. 200).

\subsection{Os saberes a ensinar}

O primeiro pressuposto para ensinar História é dominar os saberes a ensinar, pois não se ensina aquilo que não se tem. Quando referimos os saberes a ensinar, não nos restringimos ao domínio dos conteúdos convencionais da História, daqueles que são apresentados como canônicos nos livros didáticos de História. Todo professor de História, para poder ensinar, deve antes que nada, saber História. Para superar a escola vazia de conhecimentos significativos é 
necessário que os docentes alcancem um domínio complexo daqueles conteúdos que têm de ensinar, sob pena de se limitarem ao domínio da forma sem conteúdo.

O conhecimento histórico é o insumo que possibilita ao professor selecionar conceitos e informação histórica com critérios cientificamente fundamentados. Um sólido conhecimento da matéria a ser ensinada, acreditamos, implica conhecer a natureza e a estrutura do conhecimento, sua matriz disciplinar e métodos de investigação.

O conjunto de decisões de um professor de História sobre o modo de organizar e entender os conteúdos e sobre a forma de ensiná-los depende da concepção que tem de História, implícita ou explicitamente. Isto é, depende da forma como entende aspectos básicos como o papel das fontes e sua relação com o trabalho do historiador; as temporalidades e a ideia de evolução; as noções de causas-efeitos e multicausalidades, de mudança e continuidade; o papel dos acontecimentos nas conjunturas e estruturas; o lugar dos sujeitos históricos nas sociedades pretéritas, dentre tantos outros.

O professor é aquele que sabe antes que os alunos e pode traçar os itinerários mais adequados para conduzi-los à aprendizagem. Supõe-se, portanto, que o professor deva conhecer a historicidade dos saberes a ensinar; a natureza dos conceitos, os procedimentos lógicos e investigativos que orientam a produção do conhecimento científico na sua área; a amplitude e profundidade dos conteúdos; a relevância, a hierarquia, os princípios organizadores e a interação complexa entre os elementos que compõem o saber disciplinar (ACOSTA, 2013). Supõe-se, ainda, que saiba distinguir o essencial do secundário para, assim, ajustar os saberes a ensinar com o tempo escolar (institucional) e com o tempo da aprendizagem (estudante). Libâneo (2011, p. 189) sintetiza essas tarefas na ideia de que o professor tem como função primordial auxiliar os alunos a pensar teoricamente, o que implica, para este autor, "dominar os processos mentais pelos quais chegamos aos conceitos e às competências cognitivas, significa dominar os procedimentos metodológicos das ciências, para aprender a pensar cientificamente".

Lembremos aqui do pressuposto defendido por Michel de Montaigne e amplamente difundido por Edgar Morin (2003), de que mais vale uma cabeça 
bem-feita do que uma cabeça bem cheia. Tomando como referência o papel do professor de História, as tarefas podem seu sumarizadas, dentre outras, nos seguintes aspectos:

- Conhecer o valor epistemológico do que se ensina e por que se ensina de tal modo.

- Explicitar a corrente historiográfica a partir da qual se trabalha.

- Fundamentar a seleção e a organização dos conteúdos para a utilização de determinadas metodologias e não outras.

- Dar lugar a diferentes interpretações, cotejar distintas ou divergentes versões e situá-las nos debates historiográficos contemporâneos.

- Contemplar os conceitos estruturantes próprios da disciplina, dentre os quais: tempo histórico, sujeito histórico, fontes, causalidade/multicausalidade, empatia, passado, memória, história.

- Refletir sobre a responsabilidade social e o compromisso ético-político do que se ensina, problematizando sobre o sentido e a utilidade do conhecimento histórico escolar.

Essa última tarefa listada merece um comentário a parte, uma vez que ela se situa exatamente no cerne do que se considera o campo epistemológico da História. Reportemo-nos à célebre frase de George Orwell, que consta em seu livro 1984, escrito em 1948 (note-se os dois últimos dígitos invertidos no título) e publicado no ano de 1949, cujo significado está diretamente referenciado no traumático pós-1945: "Quem controla o passado, controla o futuro e quem controla o presente, controla o passado" (ORWELL, 1982, p. 36). Não se trata de afirmar a morte do passado ou a eternização do presente, mas de reconhecer que a História conhecimento é um discurso sobre o passado e, como tal, contém questões e representações do contexto em que esse discurso foi formulado.

\subsection{Os saberes para ensinar}

O domínio amplo e profundo dos conhecimentos produzidos no âmbito da ciência de referência é uma condição necessária, diria mesmo fundamental, para que o professor possa ensinar, mas não é uma condição suficiente. Esse posicionamento é corroborado por Pagés (2004, p. 156), quando questiona as 
razões dos vultosos problemas concernentes à aprendizagem da História que ora se enfrentam:

Sigue habiendo profesores y profesoras, políticos y ministras, que creen que para enseñar es suficiente con saber aquello que debe enseñarse. Para enseñar matemáticas basta con saber matemáticas, de la misma manera que para enseñar historia basta con saber historia. Si eso fuera así, sería difícil explicar porqué existen tantos problemas en el aprendizaje de la historia - o de cualquier otra materia -, porqué existen tantos jóvenes y adultos que no saben historia o saben muy poca cuando quienes les enseñan han acreditado sus saberes en la Universidad.

Na mesma direção, Bransford et al. (2007, p. 204) reiteram a validade de se operar de forma interativa o conhecimento disciplinar e o conhecimento pedagógico para se evitar determinados equívocos acerca dos saberes docentes. Dizem os autores: "Esses equívocos incluem ideias como a de que o ensino consiste apenas em um conjunto de métodos genéricos, que o bom professor pode ensinar qualquer matéria, ou que o conhecimento do conteúdo, por si só, é suficiente".

Ensinar pode ser considerada uma tarefa relativamente fácil quando não consideramos a sua relação imediata com o aprender. Nesse sentido, ensinar é fácil, bem mais difícil é fazer o outro aprender, bem mais difícil é criar condições para que outro sujeito possa mobilizar-se intelectualmente, bem mais difícil é levar o eu empírico a constituir-se como um eu epistêmico, como desafia Charlot (2006, p.12), criando pontes para passar do "indivíduo preso no movimento da vida cotidiana ao indivíduo intelectualmente mobilizado, atento ao saber", que estabelece uma relação qualificada com este saber.

Nessa perspectiva, entendemos a tarefa de ensinar como a apropriação, pelo professor, de conhecimentos pedagógicos que the permita mobilizar estratégias e recursos que transformem os conhecimentos científicos em "saberes escolares ensináveis", em conhecimentos válidos socialmente, pertinentes às características e finalidades da escola nas sociedades contemporâneas e que produzam sentido àqueles/naqueles que são os aprendentes.

A tarefa de ensinar passa pela decodificação da cultura disponível e é feita por um mediador decisivo que se interpõe entre o chamado currículo prescrito e 
os alunos: o professor. O que ensinamos cotidianamente nas escolas é uma adaptação transfigurada de forma pedagógica da cultura disponível na sociedade, conforme Acosta (2013, p. 189):

\begin{abstract}
O que os professores ensinam é o resultado de um processo de decodificação - interpretação, significação, recriação, reinterpretação, etc. - de ideias, condições e práticas que se tornam mais ou menos visíveis e viáveis em um contexto situacional de interação e intercâmbio de significados.
\end{abstract}

É o professor quem interpreta a partitura do currículo para o ensino nas escolas e salas de aula, mas suas ações e decisões não se dão no vazio e sim num contexto institucional, como ensina Acosta (2013), cujas regras de funcionamento são estabelecidas tanto no seu interior quanto externamente a ele. Internamente, incidem as relações de poder vivenciadas pelo conjunto de atores da comunidade escolar (pais, gestores, funcionários, professores, alunos), ao passo que externamente o trabalho do professor é impactado pelas políticas educacionais e curriculares, pelos agentes de governo, pelas demandas da sociedade em cada época, pelo mercado editorial de produção de materiais escolares e, até mesmo, pela tradição. Assim, Acosta (2013, p. 190) afirma que o professor opera nos limites de uma "mediação condicionada", pois, se nem tudo está determinado, também nem tudo é invenção. Os saberes ensinados e as práticas decorrentes dos processos educativos em sala de aula constituem uma mescla de tradição e de inovação.

Cabe mencionar aqui outro conceito central na compreensão da tarefa de ensinar, que Libâneo (2011, p. 192) define como "mediação didática, isto é, o ensino como atividade de mediação para promover o encontro educativoformativo entre o aluno e a matéria de ensino, explicitando o vínculo entre teoria do ensino e teoria do conhecimento". Depreende-se dessa definição que ensinar História não se reduz ao domínio do conhecimento histórico, pois existem enfoques específicos sobre os conteúdos e sobre as metodologias que requerem o estabelecimento de relações estreitas entre a teoria e a prática. A Didática da História, nesta perspectiva, é o espaço de síntese e de integração entre a formação disciplinar específica e a formação pedagógica, que propicia a 
construção de ferramentas teóricas e metodológicas para o desempenho da prática docente.

Dentre os elementos que compõem a tarefa de ensinar do professor de História, pode-se elencar a necessidade de contextualizar os espaços educativos onde se inscreve o trabalho docente; apropriar-se de marcos teóricos que possibilitem analisar a complexa trama onde as práticas educativas se produzem e reproduzem; ir além de aprender História para si, já que precisa ensinar outros a pensar historicamente de maneira crítica; buscar e construir propostas alternativas de ensino; colocar em cena propostas de relações não anacrônicas entre o passado e o tempo presente; mobilizar metodologias que contemplem o trabalho com fontes históricas e com meios audiovisuais, a resolução de problemas, o uso de categorias temporais, mudanças e permanências, dentre outras.

Pagés (2004) dimensiona as tarefas do professor de História em duas principais competências, sendo uma acadêmica e outra pedagógica. Dentre as competências acadêmicas o autor assinala aquelas relacionadas com a natureza e os procedimentos do conhecimento histórico, como as principais tendências historiográficas e sua evolução, o tipo de conceitos, datas e fatos de que se utiliza a História, além do caráter não absoluto da interpretação histórica. Ainda, elenca a compreensão dos sistemas de orientação temporal e espacial e o entendimento da História como processo. As competências pedagógicas, por sua vez, o autor as classifica em três dimensões, a saber: a aquisição de capacidades sociais e comunicativas; a concepção e o planejamento da atividade docente; e a organização, direcionamento e avaliação dos processos escolares de ensinaraprender.

\subsection{Os saberes do aprender}

Se o problema epistemológico da História é compreender como as sociedades pretéritas responderam aos desafios e demandas do seu tempo, o problema pedagógico do ensino de História é organizar os conhecimentos de modo a provocar a mobilização intelectual (CHARLOT, 2006; 2013) do aluno para que aprenda História. Assim posto, pode parecer que são questões dissociadas, mas de fato não são. Essa suposta divisão do trabalho entre o historiador e o 
professor de História da educação básica não só é reducionista quanto é perigosa, pois inviabiliza o sentido primordial da história escolar, que é desenvolver nos alunos a capacidade de pensar historicamente. Podemos questionar com Barros (2008, p. 211), como vamos ensinar os alunos a pensar a História se nós professores não o praticamos? É preciso insistir na ideia de que "ninguém promove a aprendizagem de conteúdos que não domina, a constituição de significados que não compreende, nem a autonomia que não pôde construir" (MELLO, 2000, p. 102).

Mas a tarefa de provocar a mobilização intelectual dos estudantes persiste e exige que, como professores, possamos reconhecer "quem são os que aprendem"? Isso implica fundamentalmente problematizar em que consiste a tarefa de aprender, do ponto de vista do aluno, compreendendo a estrutura da cognição e os recursos cognitivos mobilizados nas diversas situações de aprendizagem.

É um equívoco acreditar que a simples apresentação do conteúdo põe a inteligência em movimento, diz Charlot (2006; 2013), então, "a questão fundamental a ser resolvida por aquele que ensina é saber como provocar uma mobilização intelectual daquele que aprende" (CHARLOT, 2006, p. 12). O conhecimento não é mobilizado espontaneamente, imediatamente e da mesma forma por todas as pessoas que se encontram em situação de aprendizagem.

Antes de prosseguir sistematizando algumas das tarefas imputadas ao professor para "ensinar História a João", vamos identificar que aspectos da capacidade de pensar historicamente (PLÁ, 2005; CARRETERO, 2011; CARRETERO e CASTORINA, 2012) nos cabe promover nos alunos. Carretero (2011) oferece um panorama dos estudos internacionais sobre a formação do pensamento histórico, destacando alguns dos principais elementos, aqui sumarizados:

Compreensão dos conceitos históricos, caracterizados como conhecimentos conceituais e procedimentais. Os conhecimentos conceituais se distinguem entre conceitos de primeira ordem (feudalismo, democracia, socialismo, revolução etc.) e conceitos de segunda ordem (por exemplo, causalidade, progresso, evidência, fato, contexto, fontes primárias e secundárias, dentre outros). Os conhecimentos procedimentais dizem respeito à compreensão e aplicação de práticas específicas 
adotadas para o tratamento de problemas históricos, como avaliação de fontes, investigação e interpretação histórica, elaboração de argumentos fundamentados.

Representação do tempo histórico, supõe o progressivo domínio de noções relativas ao tempo, como as de ordenação temporal, duração, sucessão, simultaneidade, convenção das eras cronológicas, dentre outras.

Solução de problemas históricos, implica avaliar a complexidade dos problemas tendo em conta vários fatores inter-relacionados, buscando aproximação com o ofício do historiador, pois este trabalha com a seleção e avaliação de evidências do passado procedentes de diversas fontes para construir interpretações e explicações históricas.

Raciocínio histórico e elaboração de inferências, refere-se ao desenvolvimento de habilidades procedimentais, como avaliar a credibilidade de um texto, situá-lo em seu próprio contexto, captar seus elementos implícitos, dentre outros. A atividade docente, assim, partiria do pressuposto de que "os conteúdos de História deveriam aparecer ante o aluno como resultado de um processo de construção intelectual e não como algo cujas conclusões estão fechadas e não são suscetíveis de interpretação" (CARRETERO, 2011, p. 86).

Análise de imagens como fontes para a investigação histórica, tido como um dos pilares da aprendizagem histórica, não se resume ao tratamento de recursos pictóricos como ilustração ou comprovação de eventos pretéritos. Operar com imagens em sua condição de fonte requer um investimento rigoroso, considerando-as não só como produto historiográfico que remete a realidades passadas, mas como produto da própria história, que requer contextualização, interpretação e análise de um ponto de vista teórico.

Construção de identidades e uso de narrativas históricas na escola. A narrativa é um instrumento básico do conhecimento humano e da nossa própria constituição como sujeitos. O conhecimento histórico, por sua vez, está diretamente vinculado à elaboração de narrativas acerca das experiências humanas no tempo. Carretero (2011) diz que temos predisposição para organizar as experiências históricas mediante estruturas de tramas e que as narrativas podem prover os estudantes de conhecimentos entendidos em sua complexidade, multicausalidade e contradições. Todavia, se tratadas como unidimensionais e de 
forma descontextualizada, as narrativas podem produzir efeito diverso, como o de simplificar a abordagem da história, privilegiar algumas experiências em detrimento de outras e acentuar o papel de alguns personagens em detrimento dos distintos grupos sociais, por exemplo. Segundo o autor, as narrativas consistem numa das mais úteis ferramentas de aprendizagem histórica, mas em seu tratamento pedagógico não se pode esquecer que

[...] uno de los objetivos claros de la alfabetización histórica debe ser superar los sesgos que produce su utilización, como son la simplificación de la historia, la identificación de la historia con la narrativa en sí, el olvido de historias alternativas o la aparición de explicaciones causales sesgadas (CARRETERO, 2011, p 104).

Tendo em conta as demandas que se impõem à construção do conhecimento histórico escolar, podemos considerar algumas tarefas primordiais ao professor de História para promover a aprendizagem dos estudantes, a saber: analisar em profundidade as possibilidades e dificuldades que se apresentam nos processos de construção do conhecimento histórico; reconhecer as representações e concepções prévias dos alunos que obstaculizam e/ou potencializam as possibilidades de aprender; assumir posição de professorinvestigador da própria prática; auxiliar os jovens a compreender que os acontecimentos do passado são interpretados, invariavelmente, no contexto de uma complexa rede de relações causais e motivacionais; contribuir para o desenvolvimento do pensamento histórico dos estudantes, de modo que se apropriem de esquemas mentais de ordenamento temporal que Ihes permita operar com relações de causa-efeito, multicausalidade, mudanças e continuidades, dentre outros; identificar, de modo significativo, as relações entre as experiências atuais dos jovens e as de outros sujeitos em tempos, lugares e culturas diversas das suas; adotar estratégias que possibilitem transformar os acontecimentos contemporâneos e aqueles do passado em problemas históricos a serem estudados e investigados; considerar os processos históricos a partir do manejo de informações sobre o passado, de modo a auxiliar os jovens a compreender e expressar pontos de vista fundamentados sobre as experiências das sociedades pretéritas; colocar os estudantes diante de fontes históricas diversas, de diferentes procedências e tipologias, cotejando versões e posições, 
entendendo-as como materiais com os quais se interroga e se reconhecem as chaves de funcionamento do passado e que permitem construir inteligibilidades sobre o tempo presente; compreender a escrita da história como um processo social e cientificamente produzido, que desempenha funções na sociedade, possibilitando não só a apropriação do conhecimento histórico, como também a compreensão dos processos de produção desse conhecimento e do ofício do historiador.

\section{Considerações finais}

No enfrentamento das demandas da história escolar e na esfera da constituição dos saberes necessários à docência, alguns pensam que para ser professor de História basta conhecer o que se tem de ensinar, acreditando no conteúdo sem forma, ao passo que outros entendem que para ensinar basta contar com ferramentas pedagógicas para organizar o que se tem de ensinar, alimentando a expectativa da forma sem conteúdo. Trata-se de um obstáculo epistemológico, como diria Bachelard (1996), que precisamos superar para avançar em significação e em qualidade no âmbito do ensino-aprendizagem da História na escola. De um lado, há que superar a crença de que o conhecimento científico específico contém, em si mesmo, as chaves de sua própria compreensão e difusão. De outro lado, há que desconfiar da ideia de que a didática dá conta da tarefa de ensinar tudo a todos, como postulava Comenius ainda no século XVI, independentemente dos saberes da ciência de referência.

O que se procurou mostrar até essa altura, é que os saberes que um professor precisa manejar em situações didático-pedagógicas extrapolam em muito as relações bilaterais entre o saber histórico escolar e o conhecimento que advém da ciência de referência. O consenso, sempre provisório, sobre o que se considera "conhecimento para todos" (ACOSTA, 2013) a ser disseminado na escola é o resultado de uma complexa rede de interveniências em que entram em cena diferentes atores sociais, gestores educacionais, mercado editorial, professores, famílias, estudantes, dentre outros. Pagés (2007) diz que a história que se ensina nos diversos países é o resultado de decisões curriculares das 
quais participam técnicos, científicos e especialistas, mas tais decisões geralmente estão mediatizadas pelas lentes políticas daqueles que governam. Assim, as disciplinas escolares que alcançam o status de figurar no restrito rol que compõe o currículo escolar, ali estão em virtude de cumprir determinadas funções nos contextos políticos, sociais, culturais da sua época, em especial, para a formação cidadã das novas gerações e não, evidentemente, para profissionalizar historiadores, geógrafos, matemáticos ou linguistas. Os conhecimentos ditos científicos e os saberes escolares obedecem a lógicas e propósitos distintos, mas ambos concorrem para que se cumpram os objetivos fundamentais da História escolar.

Ao fim e ao cabo, a escola precisa contar com professores que conheçam bem os fundamentos de sua disciplina e que saibam comunicá-la aos jovens, para fazê-los pensar historicamente. Dentre os desafios essencialmente relevantes que conformam a história escolar, podemos enumerar, sinteticamente, as tarefas de interrogar os distintos contextos contemporâneos em uma perspectiva histórica, de interpretar esses contextos com o aporte da metodologia histórica e de construir a consciência cidadã sob a perspectiva da História.

\section{Referências}

ACOSTA, J. M. O currículo interpretado: o que as escolas, os professores e as professoras ensinam? In: SACRISTÁN, J. G. (Org.). Saberes e incertezas sobre o currículo. Porto Alegre: Ed. Penso, 2013, p. 188-208.

BACHELARD, G. A formação do espírito científico: contribuição para uma psicanálise do conhecimento. Rio de Janeiro: Contraponto, 1996.

BARROS, C. Propuestas para el nuevo paradigma educativo de la Historia. Clío \& Asociados. La Historia Enseñada, n. 12, p. 207-235, 2008.

BRANSFORD, J. D.; BROWN, A. L.; COCKING, R. R. (Org.). Como as pessoas aprendem: cérebro, mente, experiência. São Paulo: Ed. Senac São Paulo, 2007.

CARRETERO, M.. Comprensión y aprendizaje de la Historia. In: GUTIERREZ, Leopoldo F.R.; GARCÍA, N. G. (Org.). Enseñanza y aprendizaje de la Historia en la Educación Básica. Guauhtémoc, México: Secretaria de Educación Pública, 2011, p. 69-104. 
CARRETERO, M.; CASTORINA, J. A. La construcción del conocimiento histórico. Enseñanza, narración e identidades. Buenos Aires: Paidós, 2012.

CHARLOT, B. A pesquisa educacional entre conhecimentos, políticas e práticas: especificidades e desafios de uma área de saber. Revista Brasileira de Educação, v. 11, n. 31, p. 7-18, jan./abr. 2006.

2013.

- Da relação com o saber às práticas educativas. São Paulo: Cortez,

FORQUIN, J. C. Escola e cultura: as bases sociais e epistemológicas do conhecimento escolar. Porto Alegre: Artes Médicas, 1993.

GUMBRECHT, H. U. Depois de "depois de aprender com a história", o que fazer com o passado agora? In: NICOLAZZI, F.; MOLLO, H. M.; ARAUJO, V. L. de (Org.). Aprender com a história? O passado e o futuro de uma questão. Rio de Janeiro: Ed. FGV, 2011, p. 25-42.

LIBÂNEO, J. C. Conteúdos, formação de competências cognitivas e ensino com pesquisa: unindo ensino e modos de investigação. In: PIMENTA, S. G.; ALMEIDA, M. I. de. Pedagogia Universitária: caminhos para a formação de professores. São Paulo: Cortez, 2011, p. 188-212.

MELLO, G. N. de. Formação inicial de professores para a educação básica: uma (re)visão radical. Revista São Paulo em Perspectiva, v.14, n. 1, p. 98-110, 2000.

MORIN, E. A cabeça bem-feita: repensar a reforma, reformar o pensamento. 8 ed. Rio de Janeiro: Bertrand Brasil, 2003.

ORWELL, G. 1984. São Paulo: Editora Nacional, 1982.

PAGÉS, J. Enseñar a enseñar Historia: la formación didáctica de los futuros professores. Miradas a la historia: reflexiones historiográficas en recuerdo de Miguel Rodríguez Llopis. Coord. por José Antonio Gómez Hernández, María Encarna Nicolás Marín, 2004, p. 155-178.

. ¿Qué se debería enseñar de historia hoy en la escuela obligatoria?, ¿qué deberían aprender, y cómo, los niños y las niñas y los y las jóvenes del pasado? Revista 6 Escuela de Historia. Año 6, v. 1, n. 6, 2007. Disponível em http://www.unsa.edu.ar/histocat/revista/revista0602.htm. Acesso em 15 jun. 2015.

PAIS, J. M. Culturas Juvenis. Lisboa: Imprensa Nacional, 1996.

PLÁ, S. Aprender a pensar historicamente. La escritura de la historia en el bachillerato. México, DF: Plaza y Valdez Editores, 2005.

PRATS, J. Ensinar história no contexto das ciências sociais: princípios básicos. Revista Educar, Curitiba, n. esp., p. 191-218, 2006. 
Entrevista. Revista Escuela, n. 3753 (915), jun./2007. Disponível em http://histodidactica.es/articulos/Escuela-Prats.pdf. Acesso em 9 de janeiro de 2012.

RÜSEN, J. A Razão histórica. Teoria da História: os fundamentos da ciência histórica. Brasília: Ed. UnB, 2001.

Recebido em 19 de novembro de 2014

Aprovado em 18 de dezembro de 2015 